Nghiên cứu chỉ ra được một số yếu tố ảnh hưởng tới tuân thủ sử dụng thuốc của một số bệnh nhân như: kiến thức về bệnh, biến cố bất lợi trong quá trình điều trị. Qua đó, Trung tâm có thể thực hiện các biện pháp can thiệp nhằm nâng cao tuân thủ sử dụng thuốc của bệnh nhân hơn nữa và duy trì được tình hình tuân thủ sử dụng thuốc như tại thời điểm chúng tôi tiến hành nghiên cứu.

\section{KẾT LUẬN}

Một số yếu tố liên quan tới sự tuân thủ thuốc là số thuốc huyết áp phải sử dụng, số bệnh mắc kèm theo. Tỷ lệ bệnh nhân đạt huyết áp mục tiêu của việc tuẩn thủ sử dụng thuốc tốt cao gấp 2,7 lân so với bệnh nhân tuân thủ sử dụng thuốc kém.

\section{TÀI LIÊU THAM KHẢO}

1. Hội tim mạch hoc Quốc gia Viêt Nam (2018) "Khuyến cáo về chẩn đoán và điểu trị tăng huyết áp 2018".

2. Ngô Quốc Huyy (2014), Mô tả kiến thức, thực hành và các yếu tố liên quan đến tuân thủ điều trị của bênh nhân tai câu lạc bộ tăng huyết áp bệnh viện đa khoa Đổng Đa, Hà Nội 2014, Luận văn
Thạc sĩ Quản lý bệnh viện, Trường Đại học $Y$ tế công công, Hà Nôii.

3. Nguyến Thị Mỹ Hanh, Nguyễn Thị Mỹ Duyên (2013), "Khảo sát mối liên quan giữa tuân thủ dùng thuốc và kiểm soát huyết áp ở bệnh nhân tăng huyết áp đang điều trị ngoại trú", Hội nghị khoa học kỹ thuật Bệnh viện cấp cứu Trưng Vương.

4. Whelton PK, Carey RM, Aronow WS, Casey DE, Collins KJ, Himmelfarb CD, DePalma SM, Gidding $S$, Jamerson KA, Jones DW: 2017ACC/ AHA/AAPA/ABC/ACPM/AGS/APhA/ASH/ASPC/NMA/ PCNA guideline for the prevention, detection, evaluation, and management of high blood pressure in adults: a report of the American College of Cardiology/American Heart Association Task Force on Clinical Practice Guidelines. Journal of the American College of Cardiology 2018, 71(19):e127-e248.

5. Lam WY, Fresco P: Medication adherence measures: an overview.BioMed research international 2015, 2015.

6. Nguyen T, Cao HT, Quach DN, Le KK, Au SX, Pham ST, Nguyen TH, Pham TT, Taxis K: The Vietnamese Version of the Brief Illness Perception Questionnaire and the Beliefs about Medicines Questionnaire: Translation and Cross-cultural Adaptation.Tropical Medicine \& International Health 2019, 24(12):1465-1474.

\title{
U DÂY THẦN KINH SỐ VIII DANG NANG: KẾT QUẢ ĐIỀU TRI PHẪU THUẬT TẠI BỆNH VIỆN VIỆT ĐỨC
}

\section{TÓM TẮT}

Muc tiêu Đánh giá kết quả điều trị phẫu thuật u dây thần kinh số VIII dang nang. Đối tượng và phương pháp nghiên cứu: Nghiên cứu hồi cứu 35 trường hợp u dây VIII dạng nang được điều trị phẫu thuât tai bênh viện Viêtt Đức từ 1.2017 đến 6.2020 .

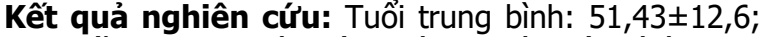
nữ chiếm $37,14 \%$ và không có sự khác biệt có ý nghĩa thống kê về giới. Ù tai là triệu chứng thường gặp nhất $(85,71 \%) ;$ có $5,71 \%$ trường hợp liệt măt trước mổ. Có 16 bệnh nhân $(45,71 \%)$ u ở độ III và IV theo phân độ KOOS. Kích thước trung bình của u là $38,35 \pm 6,25$ (mm). Phẫu thuật với đường mổ sau xoang sigma $(77,14 \%)$ là phưởng pháp mổ chính. Kết luận: Không có sự khác biệt về triệu chứng lâm sàng của u dây VIII dạng nang với các u dây VIII khác. Phẫu thuật với đường mổ sau xoang sigma là phương pháp an

\footnotetext{
${ }^{1}$ Bệnh viện Việt Đức

${ }^{2}$ Đại họ Y Hà nọi

Chiu trách nhiệm chính: Ngô Manh Hùng

Email: ngomanhhung2000@gmail.com

Ngày nhận bài: 6.01.2021

Ngày phản biện khoa học: 4.3.2021

Ngày duyệt bài: 15.3.2021
}

Ngô Mạnh Hùng1, Nguyễn Đức Nghĩa ${ }^{2}$

toàn, có hiệu quả cả về mức độ lấy u và chức năng thần kinh mặt.

Tư khoá: u dây thần kinh số VIII; u dạng nang; kết quả điều trị phẫu thuật

\section{SUMMARY}

THE CYSTIC ACOUSTIC NEUROMA: SURGICAL RESULTS AT VIET-DUC HOSPITAL

Objective: Assesment of surgical results of the cystic acoustic neuroma. Patients and methods: A cross-section, descriptive and retrospective study with 35 patients who were diagnosed, surgically treated of cystic acoustic neuroma at Viet-Duc hospital from Jan 2017 to June 2020. Results: mean age: $51.43 \pm 12.6$ (years); female $(37.14 \%)$ and there was no significant difference between the male and the female. Tinnitus was the most common symptoms $(85,71 \%)$ and there was 5.71 percent of patients with facial palsy at diagnosis time. There were sixteen patients $(45.71 \%)$ of tumor in grade III and IV of KOOS grade classification. The mean diametter of tumors was $38.35 \pm 6.25(\mathrm{~mm})$. The most patients were operated with retrosigmoid approach. Conclusion: There was no difference in the symptoms in the cystic acoustic neuroma compared the acoustic neuroma. The retrosigmoid approach was the usefulnes and safely procedure, both the level of remove of tumor and 
facical function preservation.

Keywords: acoustic neuroma; cystic tumor; outcome surgical treatment

\section{I. ĐẶT VẤN ĐỀ}

U dây thân kinh số VIII là các khối u lành tính, chiếm khoảng 8-10\% tổng số u nội sọ và $80 \%$ số các u vùng góc câu tiểu não. Tỉ lệ u dây VIII dạng nang đã được thông báo chiếm từ 11,3-24\% tổng số u dây VIII. U dây VIII dạng nang đặc trưng bởi thời gian mang bệnh ngắn, u phát triển với tốc độ nhanh, và thường có tổn thương thân kinh mặt [1]. Chính vì vậy, điêuu trị phẫu thuật u dây VIII dạng nang thường khó khăn hơn, có nhiều biến chứng hơn, nguy cơ liệt thân kinh mặt cao hơn so với u dây VIII thông thường. Để có thêm hiểu biết về các nguy cơ và khó khăn này, chúng tôi tiến hành nghiên cứu hôi cứu các trường hợp u dây VIII dạng nang, tại trung tâm phẫu thuật Thân kinh, bệnh viện Việt Đức, với mục đích đánh giá kết quả điều trị phẫu thuật.

\section{II. ĐỐl TƯƠNGG VÀ PHƯƠNG PHÁP NGHIÊN CỨU}

2.1. Đối tượng nghiên cứu. Chúng tôi tiến hành hồi cứu 35 trường hợp u dây thân kinh số VIII một bên, độ IV theo phân độ KOOS trong thời gian từ 1.2017 đến 6.2020, đã được điều trị tại trung tâm phẫu thuật thân kinh, bệnh viện Việt Đức.

\section{Tiêu chuẩn lựa chọn bệnh nhân}

- Bệnh nhân có u dây VIII một bên mới được chẩn đoán; được điều trị phẫu thuật và có kết quả mô bệnh học là u thần kinh.

- Hình ảnh u trên phim cộng hưởng từ là ở dạng nang

- Bệnh nhân không ở nhóm hội chứng u xơ thân kinh loại II (NF2)

- Bệnh nhân chưa được điêu trị bằng xạ trị/gamma knife trước đây

- Bệnh nhân có đủ hồ sơ bệnh án theo các tham số nghiên cứu

Tiêu chuẩn loại trư. Bệnh nhân không có một trong các tiêu chuẩn lựa chọn ở trên.

\subsection{Phương pháp nghiên cứu}

- Phương pháp nghiên cứu : hồi cứu, mô tả

- Các chỉ số nghiên cứu: tuổi, giới, thời gian xuất hiện triệu chứng, triệu chứng lâm sàng khi được chẩn đoán, kích thước (lớn nhất) của khối u, phân độ KOOS u trên phim cộng hưởng từ; theo dõi tình trạng liệt mặt với phân độ HouseBrackmann

- Các chỉ số nghiên cứu được thu thập, xử lý bằng phân mêm SPSS và xử lý theo các thuật toán thống kê thông thường.
- Đạo đức trong nghiên cứu: đề cương nghiên cứu đã được hội đồng đạo đức Trường Đại học Y Hà Nội chấp nhận. Mọi thông tin của BN được bảo mật và chỉ sử dụng với mục đích y khoa.

- Xü lí số liệu: theo các thuật toán thống kê thông thường, sử dụng phân mềm SPSS 20.0.

\section{KẾT QUẢ NGHIÊN CỨU}

Nhóm 35 bệnh nhân nghiên cứu bao gồm 13 bệnh nhân nữ $(37,14 \%)$ và 23 bệnh nhân nam $(62,86 \%)$, không có sự khác biệt có ý nghĩa thống kê về tỉ lệ giới tính.

Tuổi trung bình của nhóm nghiên cứu là $51,43 \pm 12,6$, thay đổi từ 23-72 tuổi.

Thời gian kể từ khi có triệu chứng đến khi được chẩn đoán thay đổi từ 8-26 tháng, trung

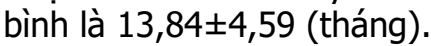

Bảng 1. Triệu chứng lâm sàng

\begin{tabular}{|c|c|c|}
\hline Triệu chứng & Số lượng & Tỉ lệ \% \\
\hline Ú tai & 30 & 85,71 \\
\hline Chóng mặt & 27 & 77,14 \\
\hline Điếc & 29 & 82,85 \\
\hline Rối loạn thăng bằng & 20 & 57,14 \\
\hline Nuốt sặ, nghẹn & 12 & 34,28 \\
\hline Liệt mặt & 2 & 5,71 \\
\hline Đau nửa mặt & 5 & 14,28 \\
\hline
\end{tabular}

Triệu chứng thường gặp nhất là ù tai $(85,71 \%)$; liệt dây VII (liệt mặt) chỉ gặp 5,71\% số trường hợp

Bảng 2. Đặc điểm của u trên phim cộng hưởng tư trước mổ

\begin{tabular}{|c|c|c|c|}
\hline \multicolumn{2}{|c|}{ Đăc điếm } & Số lượng & Tỉ lệ \\
\hline \multirow{2}{*}{$\begin{array}{c}\text { Bên tốn } \\
\text { thương }\end{array}$} & Phải & 23 & 65,71 \\
\cline { 2 - 4 } & Trái & 12 & 34,28 \\
\hline \multirow{3}{*}{$\begin{array}{c}\text { Phân độ theo } \\
\text { KOŌS }\end{array}$} & 1 & 3 & 8,57 \\
\cline { 2 - 4 } & 2 & 16 & 45,72 \\
\cline { 2 - 4 } & 4 & 10 & 28,57 \\
\hline \multirow{2}{*}{$\begin{array}{c}\text { Kích thước u } \\
\text { (mm) }\end{array}$} & Nhỏ nhất & \multicolumn{2}{|c|}{25} \\
\cline { 2 - 4 } & Lớn nhất & \multicolumn{2}{|c|}{49} \\
\cline { 2 - 4 } & Trung bình & $38,35 \pm 6,25$ \\
\hline Tăng sinh mạch & Không & 25 & 71,43 \\
cúa khối u & Có & 10 & 28,57 \\
\hline
\end{tabular}

Bảng 3. Kết quả chụp cộng hưởng từ sau mổ theo phân độ KOOS so với trước mổ

\begin{tabular}{|c|c|c|c|}
\hline \multirow{2}{*}{$\begin{array}{c}\text { Phân độ } \\
\text { KOOS }\end{array}$} & \multicolumn{2}{|c|}{ Số lượng (\%) } & \multirow[b]{2}{*}{$\mathbf{p}$} \\
\hline & Trước mố & Sau mố & \\
\hline 0 & 0 & 15 & \multirow{5}{*}{$<0,001$} \\
\hline 1 & 3 & 10 & \\
\hline 2 & 16 & 6 & \\
\hline 3 & 10 & 3 & \\
\hline 4 & 6 & 1 & \\
\hline Tống số & 35 & 35 & \\
\hline
\end{tabular}


Trong số 35 bệnh nhân có 27 bệnh nhân được điều trị phẫu thuật bằng đường mổ sau xoang sigma và 8 trường hợp được phẫu thuật bằng đường mổ qua mê nhĩ.

Biến chứng sau mổ: có 2 trường hợp $(5,71 \%)$ dò dịch não tuỷ, điều trị nội khoa và chọc và lưu dẫn lưu dịch não tuỷ thắt lưng cho kết quả tốt. 1 trường hợp $(2,86 \%)$ viêm màng não kèm theo giãn não thất, điều trị nội khoa có kết quả sau 1 tháng. Không có chảy máu sau mổ trong nhóm nghiên cứu của chúng tôi.

Bảng 4. Tình trạng liệt dây VII sau mổ và khi khám lại

\begin{tabular}{|c|c|c|c|}
\hline \multirow{2}{*}{$\begin{array}{l}\text { Độ liệt mă̆t } \\
\text { (theo phẩn } \\
\text { độ House- } \\
\text { Brackmann) }\end{array}$} & \multicolumn{2}{|c|}{ Số lượng (\%) } & \multirow[b]{2}{*}{$\mathbf{p}$} \\
\hline & $\begin{array}{c}\text { Ngay } \\
\text { sau mổ }\end{array}$ & $\begin{array}{c}\text { Khi } \\
\text { khám lại }\end{array}$ & \\
\hline I & 8 & 20 & \multirow{6}{*}{$\begin{array}{c}P= \\
0,0024\end{array}$} \\
\hline II & 15 & 10 & \\
\hline III & 7 & 3 & \\
\hline IV & 2 & 1 & \\
\hline V & 2 & 1 & \\
\hline VI & 1 & 0 & \\
\hline Tống số & 35 & 35 & \\
\hline
\end{tabular}

Thời gian theo dõi trung bình là 26,39 $\pm 5,9$ tháng, thay đổi từ 6-48 tháng

\section{BÀN LUÂN}

U dây thần kinh số VIII, còn gọi là u thần kinh tiền đình, là một trong những dạng $u$ thường gặp nhất ở vùng góc cầu tiểu não[2]. Điều trị phẫu thuật dạng u này còn có nhiêu thách thức. Mục tiêu chính của điều trị u thần kinh số VIII là lấy tối đa, một cách an toàn u và bảo tồn chức năng của dây thần kinh mặt [3]. Có ba phương pháp chính kiểm soát u dây thần kinh số VIII là điều trị nội khoa, điều trị phẫu thuật và xạ trị, tuy nhiên ở các u dạng nang điều trị xạ trị với gamma knife hoặc cyber knife ít được khuyến cáo [4].

Tuổi trung bình của nhóm nghiên cứu của chúng tôi là 51 tuổi, tương đương với thông báo của Akinduro (53 tuổi) [3] hay Rezaii (50 tuổi) [5], cao hơn so với công bố của Thapa (46 tuổi) [2]. Tương tự với các tác giả này, chúng tôi cũng không tìm thấy sự khác biệt có ý nghĩa thống kê khi so sánh tỉ lệ giới tính.

Ù tai là triệu chứng thường gặp nhất trong nghiên cứu của chúng tôi,tương tự với công bố của nhiêuu tác giả khác [2-4, 6-8]. Giảm hoặc mất thính lực cũng là triệu chứng thường gặp, tuy nhiên, do hầu hết các u dây thần kinh VIII ở một bên, do vậy đây lại là triệu chứng ít được bệnh nhân lưu tâm nhất. $82,85 \%$ số bệnh nhần trong nghiên cứu của chúng tôi đã có giảm hoặc mất thính lực một bên khi được chẩn đoán. Con số này trong nghiên cứu của Thapa [2] là $72 \%$; Akinduro [3] là 78\%; trong khi đó Awan [8] báo cáo có đến $96 \%$ số bệnh nhân có mất thính lực một bên. Điều này được giải thích bởi u tiến triển từ từ, gây chèn ép dây thần kinh ốc tai ở lỗ tai trong một bên. Paldor và cộng sự đã xác định tốc độ phát triển của u dây VIII nói chung là $3 \mathrm{~mm} / \mathrm{năm}$, nhanh hơn ở nhóm u dạng nang (4mm/năm).

Chúng tôi đã không tìm thãy sự khác biệt có ý nghĩa thống kê nếu đánh giá vị trí của u (bảng $2 ; p=0,13)$. Kết quả này tương tự với công bố của Thapa [2].

Phân độ KOOS được sử dụng phổ biến nhằm đánh giá mức độ xâm lấn của u dây VIII vào vùng góc cầu tiểu não, phân độ càng cao mức độ chèn ép vào thân não càng mạnh. Trong nghiên cứu của chúng tôi gần một nửa số bệnh nhân có u ở độ III và IV, đã có chèn ép vào vùng góc cầu tiểu não. Điều này có thể giải thích bởi thời gian từ khi có triệu chứng cho đến khi được chẩn đoán của chúng tôi khá dài (13,84 44,59 tháng).

Hầu hết các u dây VIII dạng nang đều có

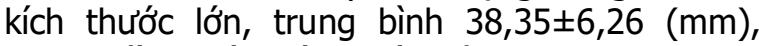
tương đồng với thông báo của Thapas $(35 \mathrm{~mm})$ [2]. Hầu hết các tác giả đều đồng thuận rằng u dây thần kinh số VIII dạng nang là một thể đặc biệt, với tốc độ phát triển nhanh, khi phát hiệ̂n ra đã có kích thước lớn và thường rất khó phẩu thuật do nguy cơ tổn thương thần kinh mặt cao hơn nhiêu so với u dạng đặc.

Tính chất tăng sinh mạch cũng là một trong các yếu tố ảnh hưởng đến quá trình phẫu thuật. Do phẫu trường hẹp, các cấu trúc quan trọng xung quanh vùng phức hợp thần kinh VII-VIII như tiểu não, đám rối mạch mạc ở lỗ Luschka, hay thân não và các mạch máu ở vùng này khiến cho việc cầm máu sẽ khó khăn hơn khi u tăng sinh mạch. Trong nghiên cứu của chúng tôi, có đến $28,57 \%$ số bệnh nhân có u tăng sinh mạch và tỉ lệ lấy hết u ở nhóm bệnh nhân này thấp hơn so với nhóm không tăng sinh mạch máu.

Đường mổ sau xoang sigma được lựa chọn ở hầu hết các bệnh nhân trong nhóm nghiên cứu của chúng tôi. Ưu điểm của đường mổ này là nhanh chóng tiếp cận tới tổn thương, có thể tiến hành cho u ở mọi kích thước và khả năng kiểm soát chảy máu quanh u tốt hơn. Nhược điểm chính của phương pháp này là khó bảo tồn dây VII hơn. Ngược lại, đường mổ qua mê nhĩ được ít được sử dụng hơn, chỉ khi chức năng nghe của bệnh nhân không còn. Uuu điểm chính của 
phương pháp này là bộc lộ được dây VII trong ống tai trước khi lấy u, vì vậy khả năng bảo tồn dây VII tốt hơn. Nhược điểm của đường mổ này là cần phải có sự phối hợp của bác sĩ tai mũi họng, chuyên sâu về đường mổ này, và vì vậy trong điều kiện tại trung tâm của chúng tôi (không có chuyên khoa tai mũi họng), khả năng phối hợp này không được áp dụng thường xuyên. Để khắc phục nhược điểm của đường mổ sau xoang sigma như đã nói ở trên, chúng tôi từ năm 2019 đã áp dụng kỹ thuật mài thành sau lỗ tai trong theo phương pháp Ohat cho kết quả tốt.

Chụp MRI sau mổ được tiến hành thường quy cho tất cả các bệnh nhẩn sau mổ, khi so sánh trước và sau mổ, theo phân độ KOOS, kích thước u giảm có ý nghĩa thống kễ (bảng 3). Chúng tôi lựa chọn mục tiêu của phẫu thuật là lấy tối đa thể tích $u$ và bảo tồn tối đa chức năng thần kinh VII, tương tự với quan điểm của Akinduro [3]. Phần u tồn dư có thể được theo dõi hoặc điêu trị xạ phẫu theo cập nhật hướng dẫn điểu trị của hiệp hội ung thư thần kinh châu Âu.

Một trong các yếu tố quan trọng khác đánh giá hiệu quả điều trị phẫu thuật là chức năng của dây VII. Khi so sánh mức độ liệt mặt theo thang điểm House-Brackmann, chúng tôi thấy có sự cải thiện có ý nghĩa thống kê. Chúng tôi giải thích hiện tượng này là bởi ngay sau mổ, tuy mức độ bảo tồn giải phẫu dây VII, song tình trạng liệt vẫn xuất hiện là do sự căng kéo, phù nể của dây VII trong mổ. Chức năng của dây VII cần phải có thời gian để phục hồi, vì vậy ở thời điểm khám lại tình trạng liệt dây VII có xu hướng tốt hởn. Các bệnh nhân trong nhóm nghiên cứu của chúng tôi thường có sự cải thiện rõ rệt tình trạng liệt mặt sau mổ ở thời điểm 6 tháng sau mổ.

\section{KẾT LUÂ̂N}

U dây thần kinh số VIII dạng nang là một thể đặc biệt của u dây thần kinh số VIII. Không có sự khác biệt về biểu hiện lâm sàng giữa dạng nang hay dạng đặc của u dây thần kinh số VIII. Tuy nhiên tốc độ phát triển của u dạng nang cao nhanh hơn so với dạng đặc. Điều trị phẫu thuật còn nhiều khó khăn do nguy cơ tổn thương dầy VII cao hơn. Đường mổ sau xoang sigma là phương pháp an toàn, có hiệu quả trong điều trị u dây thần kinh số VIII dạng nang.

\section{TÀI LIÊU THAM KHẢO}

1. Wandong, S., et al., Cystic acoustic neuroma. J Clin Neurosci, 2005. 12(3): p. 253-5.

2. Thapa, P.B., et al., Vestibular Schwanomma: An Experience in a Developing World. World J Oncol, 2019. 10(2): p. 118-122.

3. Akinduro, O.0., et al., Outcomes of large vestibular schwannomas following subtotal resection: early post-operative volume regression and facial nerve function. J Neurooncol, 2019.

4. Berkowitz, O., et al., Gamma Knife Radiosurgery for Vestibular Schwannomas and Quality of Life Evaluation. Stereotact Funct Neurosurg, 2017. 95(3): p. 166-173.

5. Rezaii, E., et al., Effect of Institutional Volume on Acoustic Neuroma Surgical Outcomes: State Inpatient Database 2009-2013. World Neurosurg, 2019. 129: p. e754-e760.

6. Lees, K.A., et al., Natural History of Sporadic Vestibular Schwannoma: A Volumetric Study of Tumor Growth. Otolaryngol Head Neck Surg, 2018. 159(3): p. 535-542.

7. Stangerup, S.E., et al., The natural history of vestibular schwannoma. Otol Neurotol, 2006. 27(4): p. 547-52.

8. Awan, M.S., et al., Vestibular schwannomas: clinical presentation, management and outcome. J Pak Med Assoc, 2001. 51(2): p. 63-7.

\section{ĐÁNH GIÁ CHỈ SỐ KHÚC XẠ GIÁC MẠC VÀ CHIỀU DÀI TRỤC NHÃN CẦU TRỂN MẤT CẦN THỊ CAO}

\section{TÓM TẮT.}

Mục tiêu: Đánh giá chỉ số khúc xạ giác mạc, chiều dài trục nhãn câu và tìm hiểu mối liển quan giữa các chỉ số khúc xạ giác mạc, chiều dài trục nhãn câu

${ }^{1}$ Bệnh viện Mắt Trung Uơng

Chịu trách nhiệm chính: Nguyễn Thị Thu Hiền

Email: thuhienvnio@gmail.com

Ngày nhận bài: 5.01.2021

Ngày phản biện khoa học: 3.3.2021

Ngày duyệt bài: 15.3.2021

\section{Nguyễn Thị Thu Hiền', Phạm Thị Minh Châu1}

trên mắt cận thị cao. Đối tượng và phương pháp nghiên cứu: nghiên cứu mố tả, nghiên cứu được thực hiện ở 88 bệnh nhân (168 mắt), tuổi từ 12 đển 47 được chẩn đoán là tật cận thị cao trên -6,00D tại khoa khúc xạ bệnh viện Trung ương. Kết quả: Độ cận trung bình là $-8,76 \pm 2.61 \mathrm{D}$. Khúc xạ giác mạc trung bình là 43,71 $\pm 1.65 \mathrm{D}$. Chiều dài trục nhãn cầu trung bình là $27,33 \pm 1,49 \mathrm{~mm}$. Khúc xa giác mạc và mức độ cận thị có tương quan tuyến tính $(r=-0,209$; $p=0,007)$. Chiều dài trục nhãn câu và mức độ cận thị cao có mối tương quan chặt chẽ với nhau $(r=-0,762$ và $p<0,001)$. Chỉ số khúc xạ giác mạc và chiêu dài 